Programa Cultura 2000. Convocatoria de propuestas 2005

> Convoca: Dirección General de Educación y Cultura de la Comisión Europea

$>$ Proyectos en el ámbito de la música y las artes escénicas, el legado cultural, las artes plásticas y visuales, la

literatura y los libros y la traducción

$>$ Cofinanciación comunitaria: hasta el $60 \%$ del coste del proyecto

> Presentación de solicitudes: hasta el 15 ó 29 de octubre de 2004, según tipo de proyecto

Más información:

Diario Oficial de la Unión Europea, C174 de 6 de julio de 2004:

http://europa.eu.int/eur-lex/pri/es/oj/dat/2004/c_174/c_17420040706es00210021.pdf

Web de la Comisión Europea:

www.europa.eu.int/comm/culture/eac/how_particip2000/pract_info/appel_2005_en.html

\title{
Metropol Parasol gana el concurso internacional de ideas de la Plaza de la Encarnación de Sevilla
}

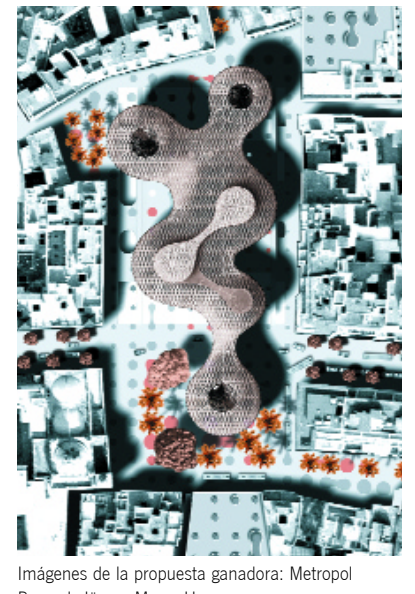

Parasol. Jünger Mayer $\mathrm{H}$.
El pasado día 12 de junio de 2004 se hizo pública la propuesta ganadora del Concurso Internacional de Ideas de la Plaza de la Encarnación de Sevilla. El equipo encabezado por el arquitecto alemán Jünger Mayer $\mathrm{H}$. y su proyecto METROPOL PARASOL deben resolver ahora una de las tareas pendientes de la ciudad de Sevilla: la Plaza de la Encarnación.

El resultado del concurso viene a completar un largo proceso caracterizado por el debate abierto a la participación ciudadana, como quedó reflejado en las dos jornadas de conferencias (19 de abril y 11 de junio) organizadas por la Gerencia de Urbanismo del Ayuntamiento de SeviIla en la Fundación El Monte. Sin olvidar la Exposición de todas las propuestas presentadas que tuvo lugar previamente en la logia del Ayuntamiento.

La Encarnación, entendida como un gran vacío urbano, debía resolver un programa de usos complejo y hacerse compatible con la conservación y puesta en valor de los restos arqueológicos. Al mismo tiempo no se debía desaprovechar la oportunidad de intervenir en un casco histórico como el de la ciudad de Sevilla, de forma que se propusieran nuevas formas de ocupar y entender un vacío que debía resolverse como un espacio público para la ciudad. Todo esto sin olvidar la importancia del transporte público, la Encarnación como intercambiador.

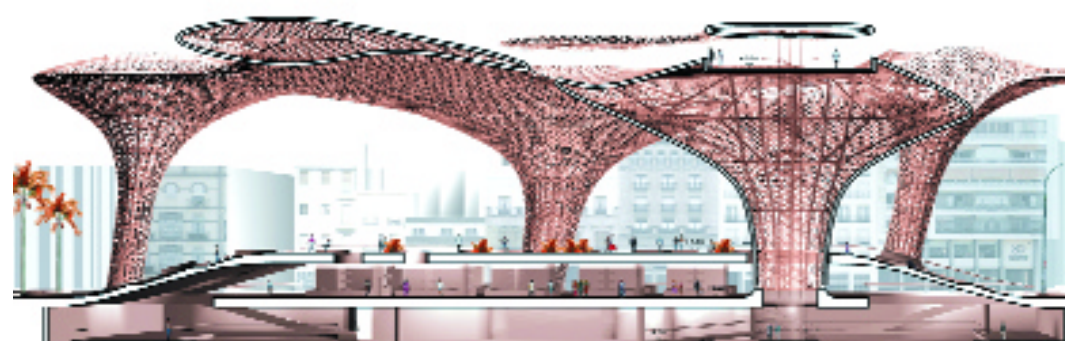

Este tipo de actuaciones deben afrontarse desde el concepto de Proyecto Patrimonial de forma que, sin entrar a valorar los 10 proyectos seleccionados en la segunda fase, se pueden reconocer las diferentes lecturas o interpretaciones del lugar, puntos de partida de las distintas soluciones aportadas, dando lugar a respuestas centradas en resolver un espacio público frente a propuestas que significan el entorno urbano mediante edificios de gran escala.

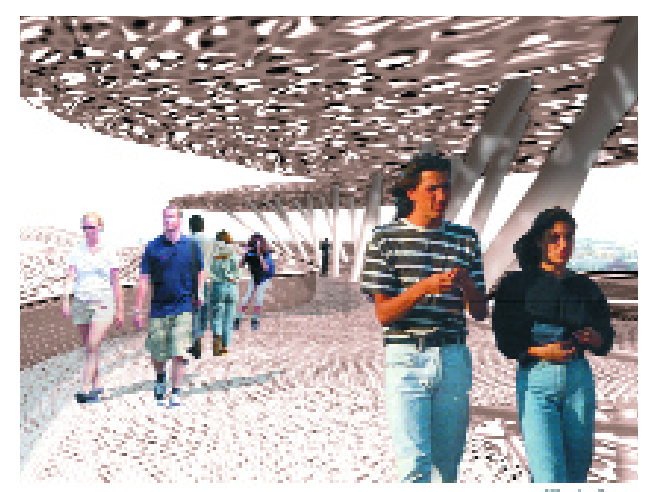

Quizá la propuesta ganadora proporciona ese entendimiento del solar como gran vacío, sin renunciar a crear una nueva imagen para la ciudad definiendo, en este caso, el Metropol Parasol, un objeto contemporáneo, contextualizado formal y funcionalmente.

Finalmente, la ciudad optó por una nueva imagen urbana, un icono. Ahora, nos queda esperar para apreciar y comprender cómo se materializa una idea, con la complejidad que supone, y cómo la ciudad asume esta nueva transformación.

Marta García de Casasola

Centro de Intervención del IAPH 